\title{
Constructing a Model Regarding Impacting Factors of the Academic Performance for Children from Transnational Marriage Families in Taiwan
}

\author{
Feng-Chiao Chung ${ }^{1}$, Kuo-Chang Wang ${ }^{2}$ \\ ${ }^{1}$ Graduate Institute of Technological and Vocational Education, National Pingtung University of Science and \\ Technology \\ ${ }^{2}$ Department of Health Promotion and Health Education, National Taiwan Normal University \\ Email: chiao366@gmail.com
}

\begin{abstract}
This study was a longitudinal follow-up study of children's development of transnational marriage families in Pingtung area of southern Taiwan. The survey population was $61 \%$ of the 115 of Taiwan surveyed in 2011 - a total of 70 students attended. Students completed demographic information and Learning Motivation scale, the mentor (teacher) filled out "The Learning Behavior Checklist for Students of Secondary School" to assess the characteristics of students' learning behavior. After the SEM statistical analysis, the findings showed that: 1. Family environment (.33) more than personal intelligence (.23) could cause children's learn motivation of transnational marriage families. 2. Family environment (-.26) was better than learning motivation $(-.25)$ to reduce the learning behavior problems of children from transnational marriage families. 3. Learning behavior problems (-.82) were better than personal intelligence (.13) to affect children's learning performance of transnational marriage families. 4. The fewer problems of learning behavior (-.64), children of the transnational marriage families had the better performance for their school achievement.
\end{abstract}

Keywords: Learning behavior, academic achievement, learning motivation

\section{Introduction}

Since the 1990s, Taiwan has rapidly transformed into a multi-ethnic society due to marital immigration. Those who enter Taiwanese society through marriage immigration include China, Southeast Asia countries such as Vietnam, Indonesia, Thailand and Philippines as well as Japan, Korea, American and western countries. At the end of 2017, there were 530,512 foreign spouses (including Mainland China, Hong Kong and Macau) who are spouses of non-Taiwanese spouses (MOI, 2017). The number of children of transnational marriage families enrolled in secondary school in 2017 amounts to 75,894, accounting for about $11.04 \%$ of the total number of national secondary schools enrolled in the country. The learning status of children from transnational marriage families in schools was an issue requiring attention in Taiwan society.

New immigrant women married into Taiwan, there were maladjustment problems due to language, culture, life, customs and environmental differences. Meanwhile, there were some characteristics for transnational marriage families, such as low social-economic status, marital instability derived from different cultures and causing distress parenting. Children of transnational marriage families had the learning difficulties and obstacles due to their lack of language skills, thereby affecting their school achievement performance and interpersonal interaction management. Furthermore, the characteristics of their families such as lack of family member timely assistance in schoolwork, and insufficient resources, might influence children's learning quality of transnational marriage families.

There were several domestic studies on topics related to students of transnational marriage families, such as academic achievements, learning behaviors and motivations (Chen, 2004; Cheng, 2011). Most of the studies regarding to students of transnational marriage families were in primary school ages; a small part of the research is in the middle school stage; a very small number of studies are in the study of the adolescent stage of learning. No study regarding to this issue belonged to a longitudinal study. In 2004, the researchers investigated the language, mental development and learning status of a total of 115 foreign spouse children in 9 elementary schools and kindergartens from 4 to 10 years old in Neipu Township, 
Pingtung County. This study showed that the language abilities of students were diversities, and there were a small number of students whose language abilities were in a state of developmental delay. Learning behaviors were also diversities. What is the current learning situation of this group of students of transnational marriage families? It's worth exploring again.

Transnational marriage families were mostly members of the lower socio-economic strata in Taiwan. Their children's development was a high-risk group with disadvantage cultures. Children's development was affected by congenital environmental stimuli, which in turn causing schooling adjustments. These derivative issues had become an important issue for domestic education authorities concerned with the development and learning of children of transnational marriage families. Studies on the academic performance of students of immigrant families, several foreign studies (Kao \& Tienda, 1995; Villiger, Wandeler, \& Niggli, 2014) had used the principle of optimism (immigrant optimism) to explain the migration of immigrants from their home countries to the development and progress of the country, in order to seek a better quality of life, if parents were actively involved in their children's education, rather than control of interfering children's learning. Their children would have superior performance in academic performance. This phenomenon was particularly manifested in Asian Americans (Dufur, Parcel, \& Troutman, 2013; Jeynes, 2002/2005), and further discovers that the expectation of the parents would have a positive impact on the children's academic achievement. In a nationwide long-term youth research database (Siahaan, Lee, \& Kalist, 2014), those who were born in the United States and whose parents were born abroad had the highest educational attainment; both children and parents born abroad, their educational achievement reached the second highest level and was higher than that of residents in the United States. As a result, it strongly supported the optimism of assimilation. That was to say, the immigrant's education success factor was that the immigrant parents attach great importance to education, and the children's language fluency contributes to their achievement performance. However, the phenomenon of immigration through marriage in Taiwan was very different from the definition of immigrants abroad. Foreign immigrants refer to the whole family moving to another country to seek a better life, but the marriage immigration in Taiwan was only women from Southeast Asia who married to a group of men of lower social stratum. This study was to investigate the performance of the children of families who have married immigrants in Taiwanese society.

Jhang \& Lee (2017) adopted the perspective of Coleman's social capital theory to discuss the influence of internal and external resources of 8,810 students in Pingtung County on the academic achievement of the 4th to 6th grade students. Family involvement included parent-child discussion, parental expectation, and family regulations, intergeneration closures, and school participation found that compared with students of this nationality, parents of students of transnational marriage families had less experience in investing in children's education. In addition to intergenerational closure, the other four dimensions had a significant correlation with the student's academic achievement.

Children born to transnational marriage families had to bear more stress and adaptation than their counterparts. The adolescent stage was a transitional period between children and adults. It was also vulnerable to the impact of their peers, or because they might give up due to difficulties in the primary school stage. The students in the stage needed further understanding and attention in academic study, interpersonal relationships, and learning conditions. It hoped to investigate their learning situation to provide assistance and advice appropriately.

In the 2006 study, there were significant differences in academic achievement between students of transnational marriage families of Southeast Asia and students of Taiwanese. However, these differences were caused by what kind of factors in the end. This study examines subtleties from the family environment, personal intelligence, learning motivation, learning behavior which factors affected the learning performance and academic performance of children of transnational marriage families. The purpose of this study was to explore the relationship between family environment(FE), personal intelligence(PI) and learning motivation(LM), learning behavior(LB), learning performance(LP), and academic performance(AP) of children of new transnational marriage families. Several assumptions would be examined in the followings.

1. There was closely relationship between learning performance and academic performance.

2. Learning behavior also affected learning performance and academic performance.

3. Learning motivation indirectly affected learning performance and academic performance through learning behavior.

4. Personal intelligence and family environment indirectly influenced learning performance and 
academic performance through learning motivation and learning behavior.

\section{Methods}

\subsection{Participants}

In this study, the researchers studied the language and mental development and learning status of 9 elementary schools and 4 to 10 year-old children of transnational marriage families in 4 primary schools and 4 kindergartens in Neipu Township, Pingtung County in 2004. In the 2011 academic year, these children had already entered the secondary and vocational high schools. This study investigated the learning situation of 70 adolescents. There were a total of 28 boys and 42 girls. Students filled in the latest exam results in terms of class ranking. There were 12 students in the ranking of top 1 to 10 in the class, accounting for $17.1 \%$ of the total. There were 17 students in the ranking class of $11-20$, accounting for $24.3 \%$ of the total. There were 32 students in the ranking class of 21 to 30 , accounting for $45.7 \%$ of the total. There were eight students in the final ranking class, account for $11.4 \%$ of the total. Only one student did not fill out his class ranking.

The mother's nationality was 3 in the Mainland, 33 in Indonesian, 14 in Vietnam, 16 in Philippines, 3 in Thailand, and 1 in Cambodia. Regarding to fathers' working condition, there were 15 students father unemployment, 43 students father of full time jobs, 7students father of part time jobs, 5 students did not fill out their father job. The average monthly household income was less than 20,000 yuan for 21 students, 20,001 yuan to 30,000 yuan for 33 students, 30,001 yuan to 40,000 yuan for 9 students, more than 40,000 yuan for 1 student. Six students did not fill out their monthly household. The demographic data of students were shown in Table 1.

Table 1. The demographic data of students from transnational marriage families

\begin{tabular}{lccc}
\hline variable & Attribute & Number & percentage \\
\hline \multirow{4}{*}{ mother's nationality } & Mainland China & 3 & 4.3 \\
& Indonesian & 33 & 47.1 \\
& Vietnam & 14 & 20.0 \\
& Philippines & 16 & 22.9 \\
& Thailand & 3 & 4.3 \\
& Cambodia & 1 & 1.4 \\
\hline \multirow{3}{*}{ Father's job } & Unemployment & 15 & 21.4 \\
& full time job & 43 & 61.4 \\
& part time job & 7 & 10.0 \\
& no data & 5 & 7.1 \\
\hline \multirow{4}{*}{ Mother's job } & Unemployment & 13 & 18.6 \\
& full time job & 47 & 67.1 \\
& part time job & 6 & 8.6 \\
& no data & 4 & 5.7 \\
\hline \multirow{3}{*}{ monthly household } & less than 20,000 yuan & 21 & 30.0 \\
& 20,001yuan 30,000yuan & 33 & 47.1 \\
& 30,001yuan 40,000yuan & 9 & 12.9 \\
& more than 40,000yuan & 1 & 1.4 \\
& no data & 6 & 8.6 \\
\hline
\end{tabular}

\subsection{Procedure}

The investigation was conducted from September to December 2011. Researcher visited each teacher in person. Questionnaire and presents were sent to the teachers. Children of transnational marriage families were required to fill out the questionnaires. 


\subsection{Instrument}

This study was a longitudinal study of the development of children of new transnational marriage families. Personal Intelligence and Family Environment Information were collected in 2004. Personal intelligence was examined by comprehensive psychological assessment. Home environment data was assessed using the home environment scale designed by Caldwell and Bradley (1984).

1. The comprehensive psychological assessment

This assessment was designed by Lin et al. (2000) which was to identify the performance of children's mental abilities. The assessment was designed fundamental by cognitive development theory, factor theory, and message processing theory which divided into A, B and C versions to assess students of different ages. This test was based on internal consistency test reliability, A-version a coefficient was from .7044 to .9249 , the average is .7802; B-version a coefficient was from .2844 to .9094 , the average was .7834. Regarding to validity, the test was based on the correlation of validity, factor analysis, and the differences between grade and gender. For the construct validity, the principal component analysis skew axis method was used to analyze the structure of factors in each version. It was found that the eight subtests A and B could all be classified into two factors. One factor was a non-language ability test, and factor 2 was a language proficiency test. Therefore, this assessment had good reliability and validity.

2. The home observations for measurement of the environment

The Home Observations for Measurement of the Environment (HOME) was designed by Caldwell and Bradley (1984). A version which was employed for 6-10 years old was conducted in the present study. The scale was a semi-structured interviewing and observation tool to assess the quality of the child's family environment. There were 59 items in total. The content mainly included parents' emotions and language reactions, mature encouragement, emotional atmosphere, fostering children's growth - things and experiences, providing active stimulation, family involvement in children's developmental stimulation experience, father involvement, and physical environment. Trained visitors to the transnational marriage families observed and interviewed mothers. HOME used a two-point system (yes/no) for each item. The score range was $0-59$ points. The higher the score indicated that the quality of home environment was better. This scale has good reliability and validity for assessing children's home environment.

3. The students learning motivation

Children of transnational marriage families were invited to fill out their demographic data and learning motivation. The Learning Motivation Scale was designed by Liu et al. (2010). This scale was applicable to the sixth grade to the ninth grade students. The scale was divided into four dimensions in terms of value, expectation, emotion and execution. Value referred to learning importance and utility. Expectations were anticipations for the success and failure of learning. Emotions contained both positive and negative moods for learning. Execution included driving for learning, persistence and seeking for perfect and other practices. There were 35 items of the Likert 5-point scale of the scale. Subjects were assessed from the complete non-conformity to full compliance with the five levels ( 1 to 5 points are assigned based on the rating, and vice versa). Accumulated subject scores on the sub-scale, which was the total score for each dimension. It took about 20 minutes to fill out this scale. Its internal consistency reliability coefficient value was between .79 and .92 . The retesting reliability coefficient value was between .64 and .76 . The criterion-related validity coefficient values ranged from .43 to .78. All of the values reached a significant level.

4. The students learning behavior assessment

Student's teachers were invited to fill out the students learning behavior assessment. This scale was designed by Meng \& Chen (2010) which was used to assess school learning behavior characteristics for the primary and secondary school students. The contents of this scale included student demographic information, academic performance, learning performance, and learning behavior scale. The teachers rated their grades as "good," "normal," "bad," and "very bad" of students' academic performance, learning performance, and learning behaviors. This scale was applicable to the first grade to the ninth grade students. The scale was divided into five dimensions including attention and memory problems, comprehension and expression problems, motivational coordination problems, social adaptation problems, and emotional performance problems. There were 80 items of the Likert 5-point scale of the scale. Subjects were assessed from the complete non-conformity to full compliance with the five levels to understand the performance frequency of students' learning behavior characteristics. The higher scores indicated that the higher of obstacles of subscales for students' learning behaviors. The reliability coefficient of internal 
consistency of the scale was .98 , the subscale was between .91 and .96 , the test-retest reliability is .78, and the subscale was between .66 and .82 . The validity of construction validity explained reached $64.90 \%$, indicating that this checklist had considerable construct validity.

\section{Findings}

Based on SEM construction of this research data, the model fitting index $\chi^{2}{ }_{\mathrm{m}}(6)=3.02(p>.05)$ of the structural model (see Figure 1) was found to be unable to reject the null hypothesis. That means this structural model was very consistent with research data. $\mathrm{CFI}=1.00$, GFI $=.98$, all greater than the proposed model evaluation criterion (.95). It indicated that the model fits well. RMSEA $=0$ is less than the proposed model assessment criterion (.05) (RMSEA 90\% confidence interval upper and lower limits equal to $0-.12$, and for $\left.\mathrm{H}_{0}: \varepsilon_{0} \leq .05, p>.05\right)$. $\mathrm{SRMR}=.03$ was also smaller than the proposed model evaluation criterion (.05). It indicated that the model fits well. This structural model adaptation with the observed covariate matrix, and the corresponding standardization residuals of each cell were less than 1.96, indicating that the model fits well. Therefore, based on the parameter estimation results of this structural model (see Table 3), it might have impact relationship between personal intelligence (IQ), family environment (FE), learning motivation (LM), learning behavior (LB), learning performance (LP), and academic performance (AP) and each other.

1. The relationship between learning performance and academic performance.

The results (see Table 2) indicated that the correlation between learning performance and academic performance was equal to .78, which was highly relevant by Cohen (1980) and also reached a statistically significant level $(p<.001)$. On the other hand, the correlation between the prediction errors of learning performance and academic performance was equal to .23, and it also reached a statistically significant level $(\mathrm{p}<.001)$ (see Table 3). Therefore, the quality of learning performance of students was closely related to the quality of their academic performance. That was, the better learning performance of students who had the better their academic performance; and the better their academic performance who had the better their learning performance.

2. The relationship between learning behavior, learning performance and academic performance

The results (see Table 3) indicated that the unnormalized estimate of the direct effect of learning behavior on learning performance is equal to -.07, while the corresponding standard error of estimation equals .01, and the ratio of the two is equal to -10.87 , which reached statistically significant level ( $\mathrm{p}$ $<$.001). Furthermore, for the variance of learning performance, the percentage of learning behavior and personal intelligence that could be explained is equal to $1-.29=.71$ (that was, $71 \%$ ). Therefore, the behavior of student's learning had a direct impact on his or her learning performance. Furthermore, students had the better learning behaviors that had the better of their learning performance. On the contrary, if the learning behavior was worse, the learning performance would be worse. And the above relationships were very strong.

On the other hand, the unnormalized estimate of the direct effect of learning behavior on academic performance was equal to -.06, while the corresponding standard error of the estimate is equal to .01, and the ratio of the two was equal to -6.01 , reaching a statistically significant level $(p<.001)$. Furthermore, for the variance of academic performance, the percentage of learning behavior that could be interpreted is equal to $1-.59=.41$ (that is, $41 \%$ ). Therefore, the behavior of the student learning behavior directly affected the quality of his or her academic performance, and this influence also had substantial significance. Furthermore, students had the better learning behaviors that had the better of their academic performance. On the contrary, if the learning behavior was worse, the academic performance would be worse. And the above relationships were very strong.

3. The relationship between learning motivation, learning behavior, learning performance and academic performance

The results of the study (see Table 3) indicated that the unnormalized estimate of the direct effect of learning motivation on learning behavior was equal to -1.25 , while the corresponding standard error of estimation equals .68, and the ratio of the two was equal to -1.83 , which is statistically significant. Level $(p<.05)$. Furthermore, for the variation in learning behavior, the percentage of learning motivation and home environment that can be explained was equal to $1-.82=.18$ (that was, $18 \%$ ). Therefore, the strength of learning motivation of students directly affected the quality of their learning behavior. 
Moreover, this influence also had a good substantive meaning. Therefore, the student learning motivation directly affected the quality of his or her learning behavior, and this influence also had substantial significance. Furthermore, students had the better learning motivation that had the better of their learning behavior. On the contrary, if the learning motivation was worse, the learning behavior would be worse. And the strength of the above relationship, although not as good as the first two, is quite significant.

Similarly, because the original model assumes that the direct effect of learning motivation on learning performance and academic performance was equal to 0 , if the direct effect path of learning motivation on learning performance and academic performance was increased in the original model, then a suitable model for the new model could be obtained. The index is $\chi^{2}{ }_{\mathrm{M}}(4)=1.49(p>.05)$. Since these two models belonged to a related hierarchical model, the chi-square difference between the two models could be used to determine whether the two added paths had reached a statistically significant level. Results indicated $\Delta \chi^{2}{ }_{\mathrm{M}}(2)=1.53(p>.05)$. That is, neither of the two added paths has reached a statistically significant level, so the direct effect of learning motivation on learning performance and academic performance was equal to zero. That was, learning motivation did not directly affect learning performance and academic performance, but indirectly affected learning performance and academic performance through learning behavior. Therefore, the motivation of the students' learning motivation was mainly through the amount of their (she) learning behaviors, which indirectly affected their (her) learning performance and academic performance.

4. The relationship between personal intelligence, home environment, learning motivation, learning behavior, learning performance and academic performance

The results of the study (see Table 3) indicated that the unnormalized estimate of the direct effect of personal intelligence on learning motivation was equal to .20, while the corresponding standard error of the estimate was equal to .11, and the ratio of the two was equal to 1.78, reaching a statistically significant level. $(p<.05)$. On the other hand, the unnormalized estimate of the direct effect of the family environment on learning motivation was equal to .69, while the corresponding standard error of the estimate was equal to .27, and the ratio of the two was equal to 2.58 , which also reached a statistically significant level $(p<.05)$. Furthermore, for the variance of learning motivation, the percentage of personal intelligence and family environment could be interpreted as equal to $1-.82=.18$ (that was, $18 \%$ ). Therefore, the level of personal intelligence of the students and the quality of the family environment directly affected the strength of their learning motivations, and this influence also had a good substantive meaning. That was to say, the better the personal intelligence and family environment of the students, the stronger the motivation for their learning. On the contrary, students had the worse the personal intelligence and family environment that they had the worse the motivation for learning. And the strength of the above relationship also had a considerable degree.

In addition, the unnormalized estimate of the direct effect of the family environment on learning behavior was equal to -2.77 , and the corresponding standard error of the estimate was equal to 1.43. The ratio of the two was equal to -1.93 , which also reached a statistically significant level $(p<.05)$. Therefore, the quality of student's family environment could also directly affect the quality of his or her learning behavior. On the other hand, the unnormalized estimate of the direct effect of personal intelligence on learning performance was equal to .05, while the corresponding estimated standard error is equal to .02, and the ratio between the two was equal to 2.11 , which also reached a statistically significant level $(p$ $<.05)$. Therefore, the level of student's personal intelligence could also directly influence the quality of his or her learning performance. Furthermore, students had higher personal intelligence that their learning performances were better. On the contrary, students had lower personal intelligence that learning performances were worse.

In conclusion, the learning performance and academic performance of the students were closely related to each other; learning behavior also directly affected learning performance and academic performance. Students had the fewer learning behavior problems, their learning performance and academic performance were better. The effect of learning behavior on learning performance $(-.82)$ was far greater than that of academic performance (-.64). Students' learning motivation indirectly affected learning performance and academic performance through learning behavior. Students had the stronger motivation for learning, they had the less the problem of learning behavior. Personal intelligence and family environment mainly affected learning performance and academic performance indirectly through learning motivation and learning behavior. Students' personal intelligences were higher; they had the stronger the motivation for 
learning. Additionally, students' family environments were better, their motivations for learning were better. The family environment (.33) was stronger than personal intelligence (.23) to arise student motivation for learning. In addition, the family environment could also directly affect learning performance and academic performance through learning behavior; the better the family environment, the fewer problems of learning behavior. The family environment (-.26) was less than learning motivation $(-.25)$ to reduce students' learning behavior problems. Students' personal intelligence could also directly affect their learning performance. However, students' learning behavior (-.82) was far more important than personal intelligence (.13) in affecting their learning performance.

Table 2. The correlation of variables with each other and their description statistics

\begin{tabular}{ccccccc}
\hline variable & $\begin{array}{c}\text { Personal } \\
\text { intelligence }\end{array}$ & $\begin{array}{c}\text { Home } \\
\text { environment }\end{array}$ & $\begin{array}{c}\text { Learning } \\
\text { motivation }\end{array}$ & $\begin{array}{c}\text { Learning } \\
\text { behavior }\end{array}$ & $\begin{array}{c}\text { Learning } \\
\text { performance }\end{array}$ & $\begin{array}{c}\text { Academic } \\
\text { performance }\end{array}$ \\
\hline Home environment & .13 & & & & & \\
Learning motivation & .27 & .31 & & & & \\
Learning behavior & -.10 & -.06 & -.34 & & & \\
Learning performance & .25 & -.003 & .24 & -.83 & & \\
Academic performance & .17 & -.02 & .21 & -.64 & 78 & \\
\hline Mean & 83.85 & 35.81 & 105.36 & 147.48 & 28.56 & 5.47 \\
SD & 13.42 & 6.56 & 11.85 & 59.81 & 5.24 & \\
\hline
\end{tabular}

Mardia's coefficient $(\mathrm{G} 2, \mathrm{P})=1.37$, Normalized estimate $=.68$, Bonett-Woodward- Randall test $(p>.05)$ shows no significant excess kurtosis indicative of non-normality

Table 3. The structural model for the influence factors of learning and academic performance, the most approximate parameter-like estimates and their standard errors

\begin{tabular}{|c|c|c|c|c|}
\hline parameter & Unstandardized & standard error & Standardized & standard error \\
\hline \multicolumn{5}{|l|}{ direct effect } \\
\hline $\mathrm{PI} \rightarrow \mathrm{LM}$ & $.20^{*}$ & .11 & .23 & .12 \\
\hline $\mathrm{FE} \rightarrow \mathrm{LM}$ & $.69^{* *}$ & .27 & .33 & .12 \\
\hline $\mathrm{PI} \rightarrow \mathrm{LP}$ & $.05^{*}$ & .02 & .13 & .06 \\
\hline $\mathrm{FE} \rightarrow \mathrm{LB}$ & $-2.77^{*}$ & 1.43 & -.26 & .13 \\
\hline $\mathrm{LM} \rightarrow \mathrm{LB}$ & $-1.25^{*}$ & .68 & -.25 & .13 \\
\hline $\mathrm{LB} \rightarrow \mathrm{LP}$ & $-.07 * * *$ & .01 & -.82 & .04 \\
\hline $\mathrm{LB} \rightarrow \mathrm{AP}$ & $-.06^{* * *}$ & .01 & -.64 & .08 \\
\hline \multicolumn{5}{|l|}{ variance \& covariance } \\
\hline $\mathrm{D}_{1}(\mathrm{LM})$ & 115.37 & 22.85 & .82 & .09 \\
\hline $\mathrm{D}_{2}(\mathrm{LB})$ & 2943 & 582.83 & .82 & .09 \\
\hline $\mathrm{D}_{3}(\mathrm{LP})$ & 7.84 & 1.55 & .29 & .07 \\
\hline $\mathrm{D}_{4}(\mathrm{AP})$ & 17.51 & 3.47 & .59 & .11 \\
\hline $\mathrm{D}_{3}(\mathrm{LP}), \mathrm{D}_{4}(\mathrm{AP})$ & 6.52 & 1.88 & .23 & .06 \\
\hline
\end{tabular}

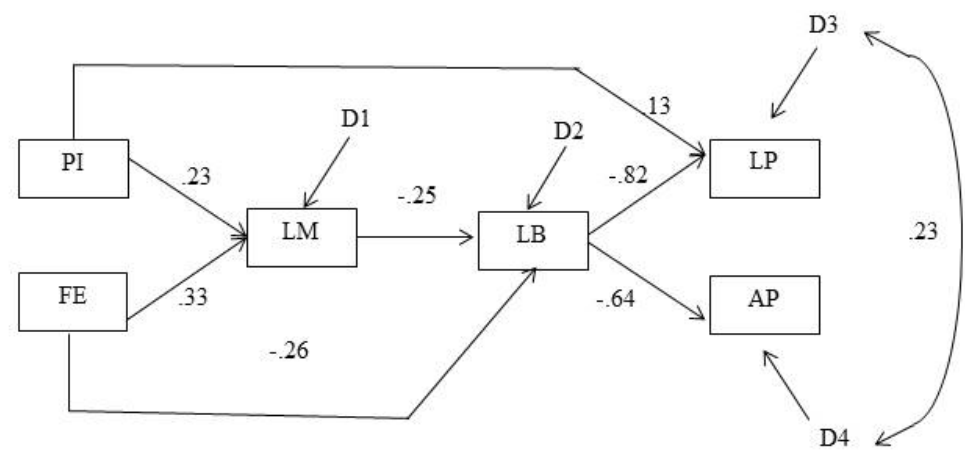

Figure 1. Influence of students' learning and academic performance 


\section{Discussion}

1. The relationship between learning performance and academic performance.

The quality of learning performance of students was closely related to the quality of their academic performance. That was, the better learning performance of students who had the better academic performance; and the better their academic performance who had the better their learning performance. Learning performance was manifested in learning and daily life, such as attention, memory, understanding, oral expression, written expression, social adaptation, and emotional expression. This means that the students of transnational marriage families with outstanding learning performance would also have excellent academic performance as a whole.

2. The relationship between learning behavior, learning performance and academic performance

Therefore, the behavior of student's learning had a direct impact on his or her learning performance. Furthermore, students had the better learning behaviors that had the better of their learning performance. On the contrary, if the learning behavior was worse, the learning performance would be worse. And the above relationships were very strong. There was a close relationship between learning performance and academic performance of students of transnational marriage families; learning behavior also directly affected learning performance and academic performance. Since the items of learning behavior were all negative topics, such as the examination would miss the topic, could not complete the work alone, the reading would jump or missing words, so learning behavior and learning performance and academic performance were closely related. That was, there was a high degree of negative correlation. Students had the fewer learning behavior problems, their learning performance and academic performance were better. And the impact of learning behavior on learning performance was far greater than the impact on academic performance.

The quality of student learning behavior directly affected the quality of his or her academic performance, and this effect also had substantial significance. In other words, the better learning behaviors of the students of transnational marriage families, the better their academic performance; on the contrary, if the learning behavior was worse, the academic performance would be worse. And the strength of the above relationship was also quite strong.

3. The relationship between learning motivation, learning behavior, learning performance and academic performance

According to studies by Chung et al. (2006) and Jhang and Lee (2017), students of transnational marriage families belonged to disadvantaged ethnic groups, so this study was to construct a learning model for disadvantaged students in Taiwan. For the disadvantaged adolescent students, the motivation of learning directly affected the quality of their learning behavior, and this effect also had good substantive meaning. That was, the stronger the motivation of the students was, the better their learning behavior would be. On the contrary, if the motivation was worse, the learning behavior would be worse. And the strength of the above relationship, although not as good as the first two, was quite significant.

For these students of transnational marriage families who were learning to be disadvantaged, the direct effect of learning motivation on learning performance and academic performance was equal to zero. That is, learning motivation did not directly affect learning performance and academic performance, but indirectly affected learning performance and academic performance through learning behavior. Therefore, the motivation of students' learning motivation was mainly through the amount of their (she) learning behaviors, which indirectly affected their (her) learning performance and academic performance. In addition, the implementation level of the motivation of the students was very low. It could be seen that the students were less motivated to learn, and they were unable to persist in the difficulties or setbacks in their academic studies and seek for excellence.

4. The relationship between personal intelligence, home environment, learning motivation, learning behavior, learning performance and academic performance

For this group of disadvantaged students, the level of personal intelligence and the quality of the family environment had a direct impact on the strength of his or her learning motivations, and this effect was also of good substantive significance. In other words, students' personal intelligence and family environment were better, their learning motivations were stronger. On the contrary, students had the worse the personal intelligence and family environment, their learning motivations were worse. And the strength of the above relationship also had a considerable degree. 
In addition, the quality of the family environment of the students can also directly affect their learning behavior. Therefore, for these learning disadvantage students, the level of personal intelligence could directly influence the learning performance. Therefore, students had higher personal intelligence, their learning performances were better, however, the lower of their personal intelligence, the worse of the learning performance. That was, although students grew in a disadvantaged family environment, if the children's intelligences were excellent, they could also exert their potential to show excellent learning performance in adversity.

In conclusion, for students of transnational marriage families who were relatively disadvantaged in Taiwan, their academic performance and learning achievement model had a close relationship with their learning performance and academic performance. Students' learning behavior directly affected their learning performance and academic performance. Students had fewer learning behavior problems, their learning performance and academic performances were better. The influence of learning behavior on learning performance was far greater than that of academic performance. Students' learning motivation, through learning behavior, indirectly affected their learning performance and academic performance; the stronger the motivation for learning, the less the problem of learning behavior. Students' personal intelligence and family environment mainly affected indirectly their learning performance and academic performance through learning motivation and learning behavior. Students had the higher the personal intelligence and the better of the family environment, their learning motivations were stronger. The family environment (.33) was stronger than personal intelligence (.23) to arise student motivation for learning. In addition, students' family environment could also directly influence their learning performance and academic performance through learning behavior; the better the family environment, the fewer problems with learning behavior; and the family environment (-.26) was more important than the learning motivation (-.25) to reduce the problem of learning behavior. Students' personal intelligence could also directly affect learning performance; however, learning behavior (-.82) was far more important than that of personal intelligence (.13) in affecting their learning performance.

European and American studies indicated there was a close relationship between the educational performance of immigrant children's children and their parents' involvement. The conditions of transnational marriage immigrants were different for studies of foreign immigrants. The women in Southeast Asia were transnational marriage immigrants to Taiwan which made their lives belonged cultural disadvantage. And their husbands with lower socioeconomic status, therefore, made them to have a double weak effect. They were also busy with their livelihoods and had no time to care for their children's learning. Although immigrant mothers were extremely concerned about their children's learning, however their involvement for children's learning might indeed be more than sufficient.

Research conducted in this study was to collect only the status of children learning behavior of transnational marriage families, it was found that also belongs to the homogeneity children of transnational marriage families (within Group differences). The analysis and comparison of the general family and students' learning behavior data were not conducted. This might be a major limitation of this study. In addition, this study did not collect children of transnational marriage families about parental involvements and an expectation of their children's learning. Several studies found that the marriage transnational marriage families in Taiwan had less involvement in their children's learning, but also because the family's social and economic status was relatively low(Dufur, Parcel, \& Troutman, 2013; Jeynes, 2002/2005; Villiger, Wandeler, \& Niggli, 2014; Jhang \& Lee, 2017). Under this double disadvantage situation, the performance of their children's academic achievements was seriously affected. The important factors affecting the performance of the children's academic achievements might be the parental involvement in their children's learning and their educational expectations for children. These factors might directly affect the performance of the children's academic achievements.

\section{Conclusion}

In 2006, the study investigated the mental development of students of transnational marriage transnational marriage families, and the children's mental and language development was diversity. The findings of this follow-up survey showed that there was a large variation in the academic performance, learning behavior, and learning motivations. Students' learning performance and academic performance were closely related to each other; learning behavior also directly affected learning performance and 
academic performance. Learning motivation, indirectly affecting students' learning performance and academic performance through learning behavior. Personal intelligence and family environment were also mainly through learning motivation and learning behavior, which indirectly affected learning performance and academic performance. This was consistent with the previous findings of the survey. The results also highlighted that the students from transnational marriage families did belonging to extremely disadvantage for their learning behaviors.

\section{References}

1. Caldwell, B., \& Bradley, R. (1984). Home Observation for Measurement of the Environment. Little Rock, AR.

2. Chen, H. C. (2004). A comparison of first graders' intelligence, language ability and school achievements between children of immigrant mothers and children of native Taiwanese mothers. Unpublished master thesis, National Tainan University.

3. Cheng, Q. (2011). Research on family reading and learning motivation of the new-residents and non-new-resident students in the new Taipei city, Unpublished master thesis, National Taipei University of Education.

4. Chung, F., Wang, K., \& Chen, Y. (2006). A comparison study of language, mental abilities development, and learning behavior for children of foreign bride families in Pingtung. Bulletin of Educational Psychology, 37(4), 411-429.

5. Dufur, M. J., Parcel, T. L., \& Troutman, K. P. (2013). Does capital at home matter more than capital at school? Social capital effects on academic achievement. Research in Social Stratification and Mobility, 31, 1-21.

6. Jeynes, W. H. (2002). The challenge of controlling for SES in social science and education research. Educational Psychology Review, 14(2), 205-221.

7. Jeynes, W. H. (2005). A meta-analysis of the relation of parental involvement to urban elementary school student academic achievement. Urban Education, 40, 237-269.

8. Jhang, F., \& Lee, Y. (2017). The role of parental involvement in academic achievement trajectories of elementary school children with Southern Asian and Taiwanese mothers. International Journal of Educational Research, .

9. Kao, G., \& Tienda, M. (1995). Optimism and achievement: The educational performance of immigrant youth. Social Science Quarterly, 76, 1-19.

10. Lin, Y. T., Wu, W. D., Wang, C. D., Tsai, C. J., Guo, J. Z., \& Hu, Z. F. (2000). Comprehensive Mental Abilities Scale, Taipei, Psychological publishing Co., Ltd.

11. Liu, C. H., Huang, P. S., Su, C. L., Chen, H. C., \& Wu, Y. C. (2010). The Development of Learning Motivation Scale for Primary and Junior High School Students, Psychological Testing, 57(3), 371-402.

12. Meng, Y. R. \& Chen, L. R. (2001). Learning Characteristics Checklist. Taipei, Psychological publishing Co., Ltd.

13. Ministry of Education Statistics (2017). Important education statistics, Retrieved June 6, 2018, from http://stats.moe.gov.tw/files/analysis/son_of_foreign_106.pdf

14. Ministry of the Interior (2017). Internal Affairs Statistics Report, Retrieved June 6, 2018, from https://www.immigration.gov.tw/ct.asp?xItem=1343512\&ctNode=29699\&mp=1

15. Siahaan, F., Lee, D. Y., \& Kalist, D. E. (2014). Educational attainment of children of immigrants: Evidence from the national longitudinal survey of youth. Economics of Educational Review, 38, 1-8.

16. Villiger, C., Wandeler, C., \& Niggli, A. (2014). Explaining differences in reading motivation between immigrant and native students: The role of parental involvement. International Journal of Educational Research, 64, 12-25. 